\title{
Gas transport and separation with ceramic membranes. Part I. Multilayer diffusion and capillary condensation
}

\author{
R.J.R. Uhlhorn*, K. Keizer and A.J. Burggraaf \\ Twente University of Technology, Faculty of Chemical Engineering, Laboratory of Inorganic Chemistry, Material Science \\ and Catalysis, P.O. Box 217, 7500 AE Enschede (Netherlands)
}

(Received october 16, 1990; accepted in revised form October 28, 1991)

\begin{abstract}
Multilayer diffusion and capillary condensation of propylene on supported $\gamma$-alumina films greatly improved the permeability and selectivity. Multilayer diffusion, occurring at relative pressures of 0.4 to 0.8 strongly increased the permeability to 6 times the Knudsen permeability, yielding permeabilities of $3.2 \times 10^{-5} \mathrm{~mol} / \mathrm{m}^{2}$-sec-Pa. The occurrence of a maximum in the permeability coincides with blocking of the pore by adsorbate (capillary condensation). This point could be predicted, employing adsorption data and the slit shape form of the pore. Separation factors of 27 were obtained with a $\mathrm{N}_{2}-\mathrm{C}_{3} \mathrm{H}_{6}$ mixture and a supported $\gamma$-alumina film, with $\mathrm{C}_{3} \mathrm{H}_{6}$ the preferentially permeating component. This very effective separation is due to pore blocking by adsorbate. The separation factor increased to 85 after modification of the system with magnesia by the reservoir method. However, the permeability of propylene decreased by a factor of 20 to $1.6 \times 10^{-6} \mathrm{~mol} / \mathrm{m}^{2}$-sec-Pa.
\end{abstract}

Keywords: ceramic membranes; diffusion; gas and vapor permeation; gas separations

\section{Introduction}

In previous articles the synthesis of ceramic $\gamma$-alumina membranes has been presented [1,2 ]. $\gamma$-Alumina membranes with a pore diameter of $3 \mathrm{~nm}$, a sharp pore size distribution and no defects have been prepared. A method to modify the chemical characteristic of the surface of the membrane and to decrease the

Correspondence to: K. Keizer, Twente University of Technology, Faculty of Chemical Engineering, Laboratory of Inorganic Chemistry, Material Science and Catalysis, P.O. Box 217, 7500 AE Enschede (Netherlands).

"Present address: Unilever Research Laboratory, P.O. Box 114, 3130 AC Vlaardingen (Netherlands). pore size has been proposed [3]. Gas separation with the non-modified as well as the modified membranes is possible by employing Knudsen diffusion [4] and surface diffusion [5]. However, these separations have a relatively low selectivity. Therefore, other separation mechanisms should be considered.

Multilayer adsorption and capillary condensation are well-known physical effects, studied and employed in many fields like catalysis and sorption technology. This article will study multilayer adsorption in combination with diffusion and capillary condensation as a means to separate condensable and non-condensable 
gases with the aforementioned $\gamma$-alumina membranes.

Very few reports exist on the use of multilayer diffusion/capillary condensation as a separation mechanism. Asaeda et al. [6-8] used a $10 \mu \mathrm{m}$ thick alumina membrane modified with non-calcined silicates to separate alcohol/water gaseous mixtures by vapor permeation and pervaporation. Separation factors for ethanol/ water mixtures exceeding 60 were found, with water being the preferentially permeating component. Such high separation factors are due to pore blocking by the condensed component (water). However, the temperature at which these membranes can be used is limited to 90 $100^{\circ} \mathrm{C}$, due to the materials used.

Although the static behavior of capillary condensate is relatively well understood [9], its dynamic behavior has been much less studied. It is very difficult to compare the scarce experimental data with theoretical predictions of the flow of adsorbable gases in the presence of capillary condensation reported in literature [1013]. Qualitatively two aspects emerge from all data. The multilayer diffusional flux is much larger than the gas phase flux (e.g. up to 20 times larger in the case of Freon on Vycor glass ). The second important aspect is that by capillary condensation a pore is blocked by condensate, preventing gas transport of other components of the gas/vapor mixture. Both aspects can result in increased selectivities.

The occurrence of multilayer diffusion and capillary condensation is mainly dependent on the relative pressure of the vapor (the ratio of the absolute pressure to the saturation vapor pressure). The relative pressure obviously is dependent on temperature and pressure. A third variable is the (mean) pore size of the membrane. Smaller pore sizes will give rise to multilayer diffusion at lower relative pressures. This parameter will be studied by modifying a $\gamma$-alumina membrane with magnesia, as described earlier [3].
First a qualitative model from the literature will be presented. Subsequently permeability data of propylene and nitrogen will be given as a function of the relative pressure of propylene. The membrane used is a supported $\gamma$-alumina thin film. These permeability data will be discussed, using the qualitative model. Separation data for a propylene/nitrogen mixture will be presented and compared to the permeability data. Finally similar experiments performed on a magnesia modified supported $\gamma$-alumina thin film will be described. A comparison with the non-modified $\gamma$-alumina film will be made to demonstrate the influence of the microstructure on the separation properties.

\section{Theory}

Multilayer adsorption occurs when a species is adsorbed in several layers. This is an extension of monolayer adsorption. Surface diffusion models, which are usually valid for up to monolayer coverage can be extended to include multilayer diffusion. Two well-known models incorporating multilayer diffusion are the hydrodynamic model [14,15] and the hopping model [16]. The first model considers the multilayer flux as a two-dimensional fluid, 'slipping' over the surface. The second model considers the flux by (non-correlated) jumps of adsorbed molecules from site to site, where the sites are not necessarily non-occupied. Details and mathematical descriptions are given in the literature [17].

As soon as capillary condensation coexists with multilayer diffusion, the transport behavior changes. The permeability for vapor flow is much higher than for liquid flow [11,15-19]. Consequently the permeability will drop as soon as all pores are filled with liquid. A plot of permeability versus relative pressure can be expected to resemble Fig. 1. Due to monolayer and subsequent multilayer diffusion, the permeability will increase until a maximum is reached 


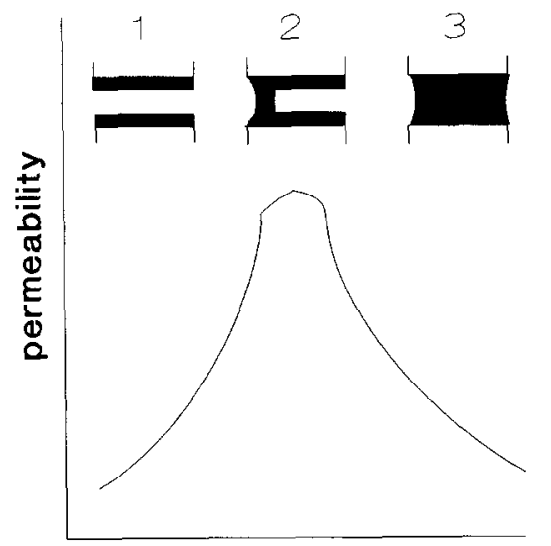

relative pressure

Fig. 1. A schematic plot of the permeability versus the relative pressure in case of multilayer diffusion and capillary condensation. The maximum gives the point of capillary condensation.

as capillary condensation starts and a liquid meniscus is formed. After this point the permeability decreases due to the liquid transport contribution.

This qualitative picture was illustrated by Lee and Hwang [19]. They used six different flow modes, schematically presented in Fig. 2. The pressures $P_{1}$ and $P_{2}$ are the upstream and downstream pressures respectively $\left(P_{1}>P_{2}\right)$. The capillary condensation pressure $P_{t}$ at temperature $T$ is predicted from the Kelvin equation:

$\frac{\rho R T}{M} \ln \frac{P_{t}}{P_{0}}=-\frac{2 \sigma \cos \theta}{r}$

where $\rho$ is the density of the condensate $(\mathrm{kg} /$ $\left.\mathrm{m}^{3}\right), P_{0}$ the temperature dependent saturation vapor pressure for a planar interface $(\mathrm{Pa}), \sigma$ the interfacial tension $(\mathrm{N} / \mathrm{m}), \theta$ the contact angle and $r$ the radius of a cylindrical capillary. The layer thickness of adsorbate $t_{i}$ (see Fig. 2) at a certain pressure $P_{i}$ and temperature $T$ is predicted by:

$t_{i}=q\left(P_{i}, T\right) \frac{V_{\mathrm{S}}}{S_{\mathrm{W}}}$
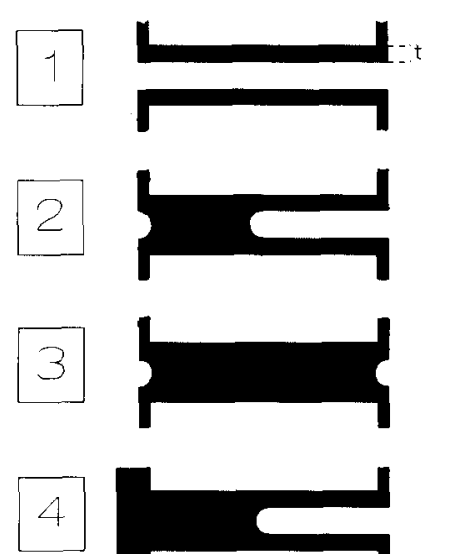

$P 2<P 1<P t$

$t P<\uparrow \uparrow<r$
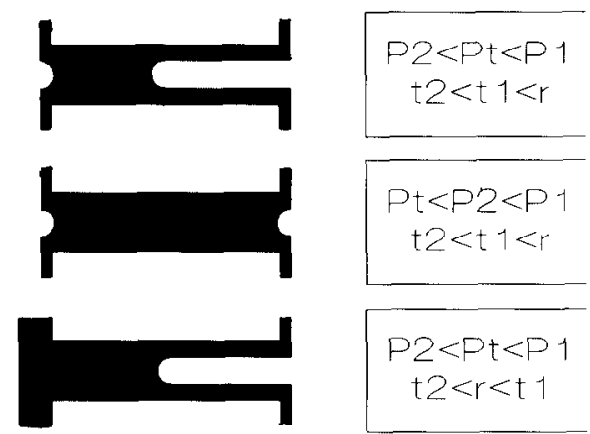

$P_{2}<P_{t}<P_{1}$

t $2<r<t_{1}$
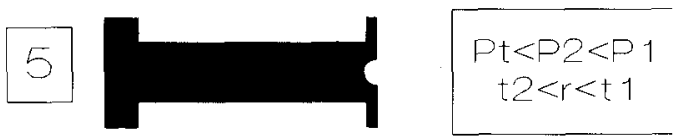

6

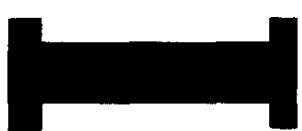

$r<t 2<t 1$

Fig. 2. Six different flow modes in multilayer diffusion and capillary condensation and their boundary conditions.

where $q(P, T)$ is the amount adsorbed $(\mathrm{g} / \mathrm{g})$, $V_{\mathrm{S}}$ the specific volume of the adsorbate $\left(\mathrm{m}^{3} / \mathrm{g}\right)$ and $S_{\mathrm{W}}$ the specific surface area of the sample $\left(\mathrm{m}^{2} / \mathrm{g}\right)$. The amount adsorbed can be predicted from e.g. the BET equation [20]:

$\frac{P_{\mathrm{r}}}{q\left(1-P_{\mathrm{r}}\right)}=\frac{1}{q_{\mathrm{m}} C}+\frac{(1-C)}{q_{\mathrm{m}} C} P_{\mathrm{r}}$

where $q_{\mathrm{m}}$ refers to the monolayer adsorption $(\mathrm{g} / \mathrm{g}), C$ is the BET constant and $P_{\mathrm{r}}$ the relative pressure $\left(P / P_{0}\right)$. The relative pressure depends on pressure as well as temperature. Equation (3) can be applied in a range of temperatures and pressures. Physically $t$ represents the thickness of the layer adsorbed on an infinite flat plate of a non-porous reference sample, equal to the porous medium.

The six possible flow modes (Fig. 2) for a cylindrical capillary in case of multilayer diffusion and capillary condensation can be explained as follows. Mode 1 in Fig. 2 represents 
the multilayer diffusion stage. The upstream and downstream pressure are smaller than the capillary condensation pressure. The adsorbate layer thickness is smaller than the pore radius. Mode 2 represents the case where capillary condensation occurs at the upstream side (thus $P_{1}>P_{t}$ ). A stable meniscus is present at the upstream side (thus $t_{1}<r$ ). The downstream pressure $P_{2}$ is however still smaller than the capillary condensation pressure. Consequently somewhere inside the pore the capillary pressure $P_{t}$ is reached $\left(P_{1}>P_{t}>P_{2}\right)$. At this point another meniscus occurs, but the matching adsorbate layer thickness (eqn. 2) is smaller than $t_{1}$. As the pore is slowly filled with liquid upon increasing $P_{2}$ mode 3 is reached. Here capillary condensation exists downstream $\left(P_{2}>P_{t}, t_{2}<r\right)$ and the whole pore is filled with liquid. If the upstream pressure is further increased but the downstream pressure remains smaller than the capillary condensation pressure, mode 4 is obtained. The upstream end of the pore will be filled with bulk condensate $\left(t_{1}>r\right)$. Mode 5 is the limiting case of mode 4 . Now the whole pore is filled with condensate $\left(P_{2}>P_{t}, t_{2}<r\right)$. Mode 6 finally presents the case where the whole pore is filled with bulk condensate $\left(t_{2}>r\right)$.

A flow mode can now be ascribed to each combination of pressure and temperature in cases where multilayer diffusion and capillary condensation exist. To each of the above described flow modes, mathematical formulations can be applied. They are presented elsewhere $[17,19]$. In this article the model is used only semi-quantitatively.

The saturation vapor pressures of propylene, used throughout this article, have been calculated by [21]:

$\log _{10} P_{0}=6.8196-\frac{785}{\left(247+t^{\prime}\right)}$

with $P_{0}$ the saturation vapor pressure $(\mathrm{mmHg})$ and $t^{\prime}$ the temperature $\left({ }^{\circ} \mathrm{C}\right)$.

\section{Experimental procedures}

Supported $\gamma$-alumina thin films were made using the slipcasting technique [2]. A supported $\gamma$-alumina thin film was modified with magnesia according to the reservoir method [3]. The whole system was impregnated with a 0.12 $M \mathrm{Mg}\left(\mathrm{NO}_{3}\right)_{2}$ and $0.24 M$ area solution, dried at $40^{\circ} \mathrm{C}$ for $3 \mathrm{hr}$ and reacted at $90^{\circ} \mathrm{C}$ for $3 \mathrm{hr}$. After the reaction, the system was calcined at $380^{\circ} \mathrm{C}$ for $3 \mathrm{hr}$. The whole impregnation cycle was repeated twice after the first treatment.

Permeability measurements were performed using several gases, employing a constant feed flow while determining the pressure difference across the membrane [17]. The temperature of the membrane was varied between -70 and $+50^{\circ} \mathrm{C}$, controlled by a cryostate. Adsorption measurements of propylene on $\gamma$-alumina were carried out using a Cahn 2000 thermo balance. The sample was first weighted and placed in the balance. After degassing at $200^{\circ} \mathrm{C}$ and 5 Torr overnight, the sample weight was determined again. The temperature was set at $0^{\circ} \mathrm{C}$, controlled by an ice bath. Then propylene was admitted and the weight increase determined. This was repeated for several pressures up to atmospheric conditions.

Separation experiments were performed using the equipment illustrated in Fig. 3. The upstream side contains a gas mixture (cylinders 1 and 2) the composition of which is controlled by Brooks type 5051 mass flow controllers $(4,5)$. This gas stream is fed through a packed bed (9) to the membrane cell (10). The upstream pressure is monitored by a pressure transducer (7) and controlled by a needle valve (11). The downstream side has no mixture option. It is fed to the membrane cell (see Fig. 3) through a packed bed (9). The downstream pressure is controlled by a needle valve (12) and monitored by a pressure transducer (8), which gives the pressure difference between the upstream and downstream side. The tempera- 


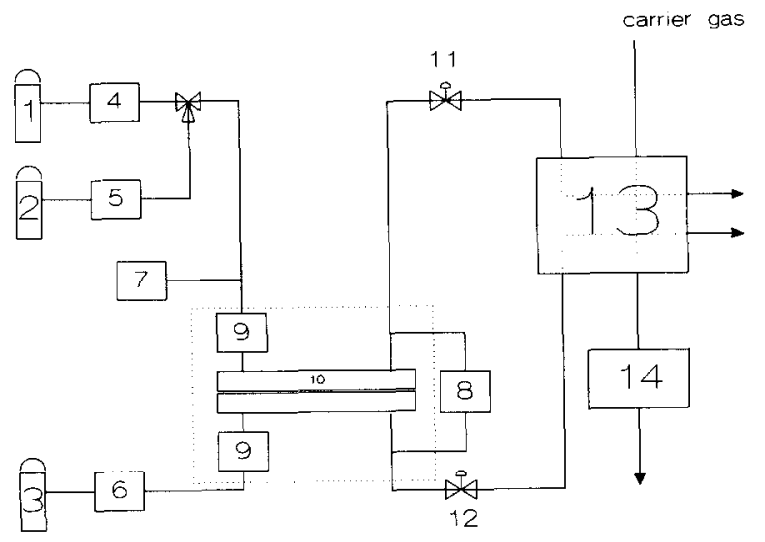

Fig. 3. Equipment for gas separation. $(1,2,3)$ gascylinders, $(4,5,6)$ mass flow controllers, $(7,8)$ pressure transducers, (9) packed bed, (10) membrane cell, $(11,12)$ needle valves, (13) ten way sample valve, (14) gas chromatograph.

ture of the membrane cell and packed beds can be controlled by an oven or cryostate (dashed line). Finally the upstream and downstream flows are sampled using a ten way sample valve (13) and analysed by a gas chromatograph (14). This set-up enables analysis of the feed flow (upstream flow) and the permeate flow (downstream flow).

Multilayer diffusion/capillary condensation experiments were carried out, using this apparatus. A vacuum pump was attached to the low pressure side after the ten way sample valve such that the permeate flow could still be sampled. This lowers the ratio of downstream to upstream pressures and minimizes the effect of backdiffusion [4,17]. A feed mixture of $61 / \mathrm{min}$, consisting of $60 \%$ propylene and $40 \%$ nitrogen, was used. The amount of $6 \mathrm{l} / \mathrm{min}$ ensures that the feed flow is at least 9 times larger than the permeate flow through the membrane. It was assumed that no concentration gradients existed across the membranes at the feed side. To reduce the effect of concentration polarization, $200 \mathrm{ml} / \mathrm{min}$ helium was used downstream as a sweep gas in a countercurrent fashion.
Results and discussion

Supported $\gamma$-alumina thin films

\section{Multilayer diffusion/capillary condensation} of propylene: permeability

In all the gas transport experiments described in this section a two layer support was used. This support consisted of a $2 \mathrm{~mm}$ thick support (pore diameter $5 \mu \mathrm{m}$, porosity $40 \%$ ) on top of which a $30 \mu \mathrm{m}$ thick intermediate layer (pore diameter $0.2 \mu \mathrm{m}$, porosity $45 \%$ ) was deposited. A $5 \mu \mathrm{m}$ thick $\gamma$-alumina film was synthesized on this support. In this configuration the resistance to gas and vapor phase transport is determined by the $\gamma$-alumina toplayer only and not by the support. All experimentally determined transport properties therefore can be assigned directly to the $\gamma$-alumina film.

Figure 4 presents the helium and propylene permeability for this system at $263 \mathrm{~K}$. Two things become clear from this figure. First the pressure independent permeability of helium (equal to $7.6 \times 10^{-6} \mathrm{~mol} / \mathrm{m}^{2}$-sec-Pa) demon-

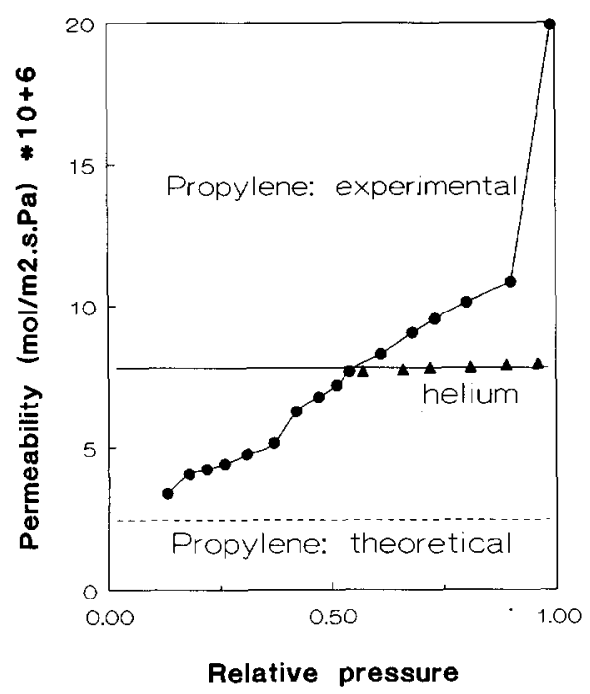

Fig. 4. Permeability of a supported $\gamma$-alumina thin film for nitrogen and propylene at $263 \mathrm{~K}$ as a function of relative pressure of propylene. Support has no influence due to use of three layer system. 
strates that the toplayer contains no defects (transport by Knudsen diffusion only). Second, the experimentally observed permeabilities of propylene are up to 9 times higher than the propylene permeability predicted from the helium permeability $\left(2.310^{-6} \mathrm{~mol} / \mathrm{m}^{2}\right.$-sec-Pa $)$ using the Knudsen diffusion assumption. Moreover, the dependence of the propylene permeability on the relative pressure agrees with the theoretical prediction (Fig. 1). Thus, first the propylene permeability increases due to multilayer diffusion. A maximum is reached, where most pores are filled with condensate. After this maximum, the permeability decreases again. part of the transport is now by liquid flow, which will decrease the total flow, as discussed in the previous section. If the relative pressure is decreased again (desorption mode), the permeability starts to rise until a maximum is reached. This maximum is reached at lower relative pressures than in the adsorption mode. At this maximum, the liquid disappears and the transport mechanism is again multilayer diffusion.

This qualitative model can be further elaborated with the model of Fig. 2, provided an estimate of the adsorbate layer thickness is made according to eqns. (2) and (3) (the BET equation). For this purpose, a study on the adsorption behavior of propylene on $\gamma$-alumina has been performed.

Table 1 gives adsorption data of propylene on $\gamma$-alumina at $273 \mathrm{~K}$. These data can be transformed into a BET plot by the use of eqn. (3). Figure 5 presents this BET plot. A least square fit of these data yields:

$\frac{P_{\mathrm{r}}}{\left(1-P_{\mathrm{r}}\right)} \frac{1}{q}=2.801+14.96 P_{\mathrm{r}}$

This equation gives the amount adsorbed $(q)$ as a function of the relative pressure. From the amount adsorbed, $q$, an adsorbate layer thickness is calculated according to eqn. (2) and the transport mode is determined from Fig. 2. The
TABLE 1

Adsorption data of propylene on non-supported $\gamma$-alumina thin films at $273 \mathrm{~K}$

\begin{tabular}{lllll}
\hline $\begin{array}{l}\text { Pressure } \\
(\mathrm{kPa})\end{array}$ & $\begin{array}{l}\text { Adsorbed } \\
\text { weight }(\mathrm{mg})\end{array}$ & $\begin{array}{l}\text { Cumulative } \\
\text { adsorbed }(\mathrm{mg})\end{array}$ & $\begin{array}{l}\text { Total } \\
\text { adsorbed } \\
(\mathrm{g} / \mathrm{g})^{1}\end{array}$ & $\begin{array}{l}\text { Rel. } \\
\text { pressure } \\
(-)^{2}\end{array}$ \\
\hline $17.5^{3}$ & 0.85 & 0.85 & 0.0088 & 0.0304 \\
31.5 & 0.67 & 1.52 & 0.0157 & 0.0547 \\
46.0 & 0.58 & 2.10 & 0.0217 & 0.0799 \\
63.2 & 0.64 & 2.74 & 0.0283 & 0.1097 \\
77.3 & 0.42 & 3.16 & 0.0327 & 0.1342 \\
95.8 & 0.43 & 3.59 & 0.0371 & 0.1663 \\
\hline
\end{tabular}

'Sample weight after degasification is $96.78 \mathrm{mg}$.

${ }^{2}$ Saturation vapor pressure at $273 \mathrm{~K}$ of propylene is $576 \mathrm{kPa}$.

${ }^{3}$ Not incorporated in the BET plot.

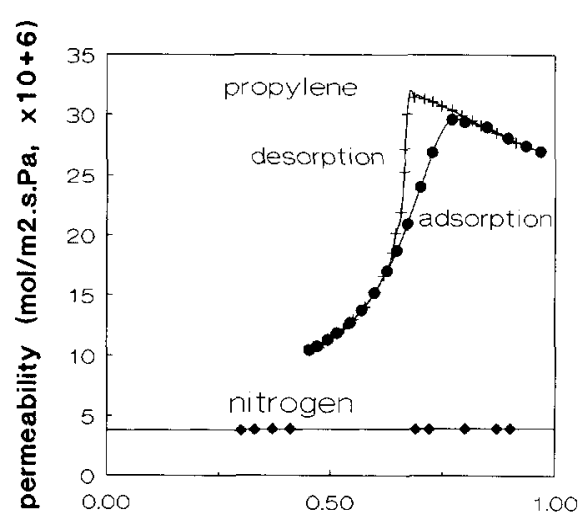

Rel. pressure

Fig. 5. Permeability of a supported $\gamma$-alumina thin film for nitrogen and propylene at $236 \mathrm{~K}$ as a function of the relative pressure of propylene.

specific surface area of the $\gamma$-alumina film is 250 $\mathrm{m}^{2} / \mathrm{g}$ [2]. The specific volume of propylene, calculated from its liquid density at $263 \mathrm{~K}$, is $0.54 \mathrm{~g} / \mathrm{cm}^{3}[22]$, resulting in a specific volume of $1.85 \times 10^{-6} \mathrm{~m}^{3} / \mathrm{g}$. Substitution of the specific volume and surface in eqn. (2) gives:

$t=7.4 q(\mathrm{~nm})$

where $q$ is estimated from eqn. (5). From eqn. (6) and the experimental data of Fig. 4, more insight can be gained in the transport behavior of propylene, as will be shown.

Table 2 summarizes the relevant data for the 
TABLE 2

Relevant data of the permeability of propylene at $263 \mathrm{~K}$ as a function of the relative pressure

\begin{tabular}{|c|c|c|c|c|c|c|}
\hline \multirow{2}{*}{$\begin{array}{l}\text { Upstream } \\
\text { pressure, } \\
P_{1}(\mathrm{kPa})\end{array}$} & \multirow{2}{*}{$\begin{array}{l}\text { Downstream } \\
\text { pressure, } \\
P_{2}(\mathrm{kPa})\end{array}$} & \multirow{2}{*}{$\begin{array}{l}\text { Relative } \\
\text { pressure } \\
(-)^{1}\end{array}$} & \multirow{2}{*}{$\begin{array}{l}\text { Permeability } \\
\left(\mathrm{mol} / \mathrm{m}^{2} \cdot \text {-sec-Pa }\right) \\
\left(\times 10^{5}\right)\end{array}$} & \multicolumn{2}{|c|}{ Adsorbate layer thickness $(\mathrm{nm})$} & \multirow{2}{*}{$\begin{array}{l}\text { Mode } \\
\text { [13] } \\
\text { (Fig. 2) }\end{array}$} \\
\hline & & & & $t_{1}\left(P_{1}\right)$ & $t_{2}\left(P_{2}\right)$ & \\
\hline 265 & 216.2 & 0.626 & 1.71 & 1.02 & 0.74 & mode 1 \\
\hline 274 & 229.6 & 0.648 & 1.87 & 1.09 & 0.80 & mode 1 \\
\hline 284 & 244.3 & 0.671 & 2.10 & 1.18 & 0.88 & mode 2 \\
\hline 296 & 261.3 & 0.700 & 2.40 & 1.31 & 0.99 & mode 2 \\
\hline 308 & 277.1 & 0.728 & 2.69 & 1.46 & 1.12 & mode 2 \\
\hline 326 & 297.7 & 0.771 & 2.96 & 1.74 & 1.32 & mode 5 \\
\hline 338 & 309.7 & 0.799 & 2.94 & 2.01 & 1.47 & mode 5 \\
\hline 359 & 330.3 & 0.849 & 2.90 & 2.68 & 1.82 & mode 6 \\
\hline
\end{tabular}

${ }^{1}$ Calculated with respect to the upstream pressure $P_{1} ; P_{0}=423 \mathrm{kPa} ; P_{t}=0.67 P_{0}$.

${ }^{2}$ The mean pore radius is assumed to be $1.5 \mathrm{~nm}$.

adsorption branch of Fig. 4, applied to the model of Fig. 2. The upstream and downstream pressure and the permeability have been determined experimentally. The capillary condensation pressure $P_{t}$, estimated from the desorption branch of Fig. 4, is $0.67 P_{0}$. The adsorbate layer thickness has been calculated from eqn. (6). The flow modes (last column) have been designated according to the conditions of pressure and adsorbate layer thickness in Fig. 2.

According to Fig. 2, capillary condensate forms in mode 2. This is also the point where the maximum permeability should be found. However, Table 2 shows this is not the case for the propylene permeability. Theoretically capillary condensation should start at an upstream pressure of $284 \mathrm{kPa}\left(P_{\mathrm{r}}=0.67\right.$, mode 2$)$, but the observed maximum permeability is found at the upstream pressure of $326 \mathrm{kPa}\left(P_{\mathrm{r}}=0.77\right.$, mode $5)$.

This apparent discrepancy could be attributed to the slit shape of the pores in the $\gamma$-alumina matrix. Previously it has been shown that a pore in the $\gamma$-alumina film is rectangular, with the length much larger than the width $[2,3]$. The multilayer adsorption process of propylene in such a pore can be compared to filling the space between two parallel, infinite plates. Capillary condensation does not occur in the adsorption mode. At a certain pressure, the adsorbate layers of the two separate plates meet; at this point the pore is filled with liquid and the adsorbate layer thickness should become equal to or larger than the pore radius of the slit shaped pore. The mean pore radius in the $\gamma$-alumina film is $1.5 \mathrm{~nm}$. Table 2 shows that the first point where the adsorbate layer thickness is larger than the pore radius is at $P_{1}=326$ $\mathrm{kPa}$. This is also the point where the highest permeability is found. Thus the slit shaped pores of the $\gamma$-alumina are filled with layers of adsorbate, until the layer thickness has become larger than the pore radius. This is the point where condensate has filled the pore, corresponding to a maximum in permeability. In terms of the model in Fig. 2, one could say mode 2 does not exist in slit shaped pores in the adsorption mode.

The preceding discussion on the propylene permeability concerned the adsorption branch. However, the evolution of the permeability in the desorption branch can be explained following the same line of reasoning. In this case, condensate has already formed. The $\gamma$-alumina film is slowly emptied of liquid upon decreasing the 
relative pressure. This decreases the contribution of liquid transport and thus increases the permeability. At the point where the (theoretical) adsorbate layer thickness becomes smaller than the pore radius, a meniscus forms, contrary to the adsorption case. This is because a liquid already exists inside the pore, as opposed to the adsorption case. Consequently the liquid will not disappear. Therefore, the maximum permeability in the desorption mode is found at lower relative pressures than in the adsorption mode (Fig. 4).

In principle it is possible to quantify the multilayer diffusion and capillary condensation of propylene further, taking into account the pore structure of the $\gamma$-alumina thin film. Theoretical models in the literature offer this opportunity [17]. A much more detailed analysis of the adsorption behavior of propylene should be conducted, however.

\section{Multilayer diffusion/capillary condensation of propylene: separation}

In the previous section it has been shown, that the transport of propylene is largely enhanced by multilayer diffusion transport. According to Fig. 4 the permselectivity (the ratio between the pure gas permeabilities) for propylene over nitrogen becomes as high as 7.4 (Knudsen factor is 0.8 ). It is expected that separation factors can become even higher due to blockage of the pore by condensate. Therefore the separation of a $60 \% \mathrm{C}_{3} \mathrm{H}_{6} / 40 \% \mathrm{~N}_{2}$ mixture employing the same system as in the permeability experiments, has been determined.

Figure 6 presents the separation factor as a function of relative pressure. The preferentially permeating component is propylene. Separation factors up to 27 (corresponding to $2.5 \% \mathrm{~N}_{2}$ in the permeate) are found. Table 3 compares some separation factors with permselectivity data, calculated from Fig. 4. This table shows, that at high relative pressures the separation factor is much higher than the

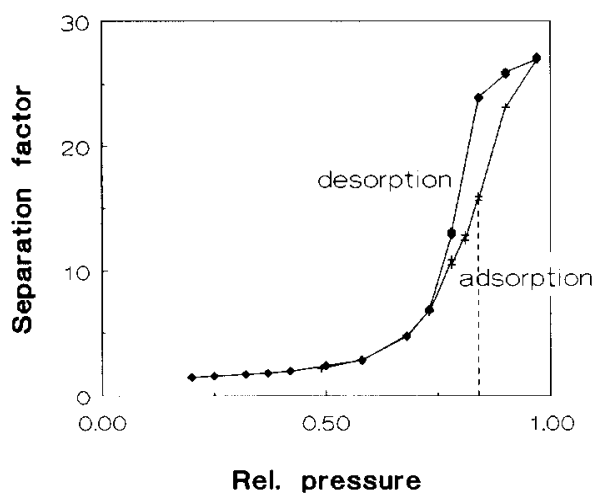

Fig. 6. The separation factor of a $\mathrm{C}_{3} \mathrm{H}_{6} / \mathrm{N}_{2}$ mixture as a function of relative pressure with a $\gamma$-alumina thin film, where $\mathrm{C}_{3} \mathrm{H}_{6}$ is the preferentially permeating component; the dashed line gives the relative pressure at which a maximum in the permeability occurs in Fig. 5 .

\section{TABLE 3}

Separation factors and permselectivities for a propylene/ nitrogen mixture, in which propylene is the preferentially permeating component, at $263 \mathrm{~K}$

\begin{tabular}{lcc}
\hline Rel. pressure & $\begin{array}{l}\text { Separation factor } \\
\text { (desorption mode) }\end{array}$ & $\begin{array}{l}\text { Permselectivity } \\
\text { (desorption mode) }\end{array}$ \\
\hline 0.97 & 27 & 6.4 \\
0.90 & 26 & 6.6 \\
0.78 & 13 & 7.1 \\
0.73 & 6.8 & 7.3 \\
0.58 & 2.9 & 3.3 \\
0.42 & 2.0 & 1.5 \\
\hline
\end{tabular}

permselectivity. This is due to blockage of the pore by propylene, which decreases the (gas phase) transport of nitrogen considerably.

It is remarkable that the separation factor starts to increase very close to the point, where the $\gamma$-alumina pores are filled with liquid (see Table 2). This point is given by the maximum of the adsorption branch in Fig. 4. The relative pressure at which this maximum occurs, is also given in Fig. 6 by a dashed line. It can be seen that the separation factor starts to increase sharply just before this point. This implies, that multilayer diffusion only becomes effective rather close to the condensation point. After 
this point, the separation factor still increases. This is probably caused by the fact that the $\gamma$-alumina thin film has a certain pore size distribution and not all pores will be filled with liquid at the same relative pressure. Therefore the separation factor still increases upon increasing the relative pressure.

The presence of condensate inside the pores is again demonstrated by the behavior of the separation factor in the desorption mode. Hysteresis is found, in accordance with the permeability measurements. Condensate inside the pores can cause blockage at relative pressures lower than in the adsorption mode. If only one single pore size existed, the separation factor would decrease sharply at one specific relative pressure. The existence of a pore size distribution in the $\gamma$-alumina film makes this decrease more gradual.

\section{Magnesia modified $\gamma$-alumina thin films}

The $\gamma$-alumina system, used in the previous sections, was subsequently modified with magnesia according to the reservoir method [3]. The drying and reaction step were performed sequentially. The whole modification treatment was performed three times, finally resulting in a (theoretical) filling of $85 \%$ of the pore volume [3]. With this modified $\gamma$-alumina system, the permeability and separation experiments with propylene and nitrogen were repeated.

Figure 7 presents the propylene and nitrogen permeability of the magnesia modified system. By comparing Fig. 7 with Fig. 5 it is clear that the permeability of propylene as well as nitrogen has decreased drastically by a factor of about 20 . This is due to the high load of magnesia, decreasing the pore volume and possibly the pore size. The propylene permeability does not show hysteresis (no difference has been found between adsorption and desorption mode at relative pressures below 0.85 ). The existence

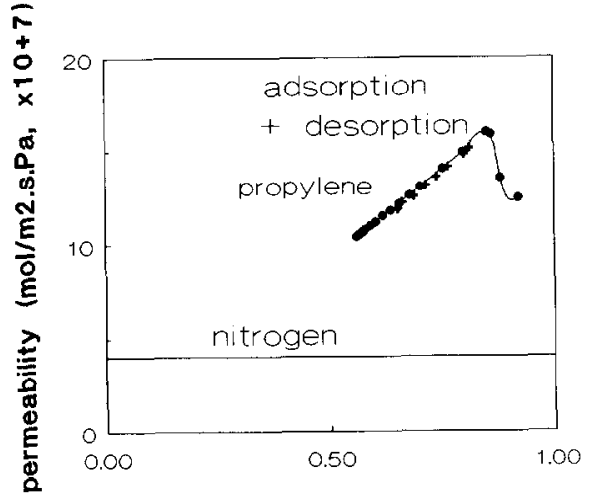

Rel. pressure

Fig. 7. Permeability of a magnesia modified supported $\gamma$ alumina thin film for nitrogen and propylene at $263 \mathrm{~K}$ as a function of relative pressure of propylene. Support has no influence.

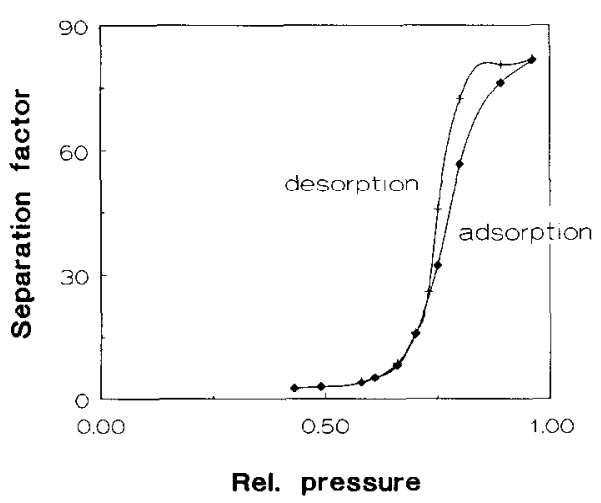

Fig. 8. The separation factor of a $\mathrm{C}_{3} \mathrm{H}_{6} / \mathrm{N}_{2}$ mixture as a function of relative pressure with a magnesia modified $\gamma$ alumina thin film, where $\mathrm{C}_{3} \mathrm{H}_{6}$ is the preferentially permeating component.

of a maximum in the curve indicates the presence of condensate in the pores.

Figure 8 presents the data of a cross flow separation experiment, with a gas mixture. Again the starting mixture consisted of $60 \%$ propylene and $40 \%$ nitrogen. At high relative pressures the separation factor increased to 85 (corresponding to $0.77 \%$ nitrogen in the permeate flow). This is much higher than the separation factor obtained with the non-modified system. Further comparison between the non- 
modified and modified system (Figs. 6 and 8 respectively) shows that in the latter vase the adsorption and desorption branch have become steeper. This means the separation factor in the modified membranes changes more sharply at a characteristic relative pressure. It indicates a more uniform pore size in the case of the modified system. Apparently the few larger pores have become smaller due to the modification treatment. Furthermore the desorption branch in Fig. 8 shifts to lower relative pressures compared with Fig. 6. This is an indication of a pore size decrease due to the modification treatment. Consequently, the pore diameter of the modified $\gamma$-alumina thin film must be below 3 $\mathrm{nm}$. However, it must be larger than $2 \mathrm{~nm}$, since hysteresis between adsorption and desorption occurs only in pores with a diameter above 2 nm (see e.g. Ref. [20]). Therefore, the mean pore diameter of the modified $\gamma$-alumina thin film is between 2 and $3 \mathrm{~nm}$, while the pore size distribution has become sharper after modification. It will be shown that it is possible to reduce the pore size even further to molecular dimensions (pore diameter $<1 \mathrm{~nm}$ ) by another modification technique [23]. This will greatly influence the transport mechanism and sharply increase the selectivity while maintaining a high permeability [23].

\section{Conclusions}

(1) Multilayer diffusion increased the propylene permeability through a supported $\gamma$-alumina thin film by a factor of 10 , compared to Knudsen transport.

(2) The point where the pores become filled with condensate is observed as a maximum in the permeability. At this point, transport is partly taken over by the slower liquid flow.

(3) A hysteresis was found between adsorption (increasing relative pressure) and desorption (decreasing relative pressure). This is due to the existence of a meniscus in the desorption mode.

(4) The permeability curve of propylene as a function of pressure could be understood by taking into account the slit shape of the pores and employing a semi-quantitative model that consists of six possible flow modes.

(5) Separation experiments with a propylene/nitrogen mixture over the $\gamma$-alumina system gave separation factors up to 27 at a relative pressure of 0.85 , where propylene is the preferentially permeating component. These high separation factors are due to blockage of the pores by (propylene) condensate.

(6) Modification of the $\gamma$-alumina system with magnesia improved the separation. In this case separation factors as high as 85 at a relative pressure of 0.80 were found. This increased separation efficiency is partly due to the disappearance of larger pores and partly to a small pore size decrease. The permeability, however, decreases by a factor of 20 compared to the propylene permeability in the non-modified system. Since it is possible to control to a large extent the modification process, it seems possible to optimize the separation factor and permeability.

(7) The advantage of using capillary condensation as a separation mechanism is the high achievable separation factors combined with very high fluxes. The disadvantage of this mechanism is, that a condensable component is necessary. So always temperature and/or pressure must be chosen in such a way, that condensation of at least one component of a mixture inside the pores of the membrane is possible. At higher temperatures this would require larger pressures.

\section{Acknowledgement}

Loek Berkeveld is gratefully thanked for preparation of the multilayer supports. The financial assistance of the Innovative Research 
Program Committee on membranes is gratefully acknowledged.

\section{References}

1 A.F.M. Leenaars, K. Keizer and A.J. Burggraaf, The preparation and characterization of alumina membranes with ultrafine pores 2 . The formation of supported membranes, J. Coll. Interf. Sci., 105 (1985) 2740.

2 R.J.R. Uhlhorn, K. Keizer and A.J. Burggraaf, Synthesis of ceramic membranes. Part I. Synthesis of nonsupported and supported $\gamma$-alumina membranes without defects, J. Mater. Sci., 27 (1992), in press.

3 R.J.R. Uhlhorn, K. Keizer and A.J. Burggraaf, Synthesis of ceramic membranes. Part II. Modification of thin alumina films: reservoir method, J. Mater. Sc., 27 (1992), in press.

4 K. Keizer, R.J.R. Uhlhorn, R.J. v. Vuren and A.J. Burggraaf, Gas separation mechanisms in microporous modified $\gamma$-alumina membranes, J. Membrane Sci., 39 (1988) 285-301.

5 R.J.R. Uhlhorn, K. Keizer and A.J. Burggraaf, Gas and surface diffusion in modified $\gamma$-alumina systems, J. Membrane Sci., 46 (1989) 225-241.

6 M. Asaeda and L.D. Du, Separation of alcohol/water gaseous mixture by a thin ceramic membrane, J. Chem. Eng. Jpn., 19(1) (1986) 72-77.

7 M. Asaeda and L.D. Du, Separation of alcohol/water gaseous mixtures by an improved ceramic membrane, J. Chem. Eng. Jpn., 19(1) (1986) 84-85.

8 S. Sakohara, S. Kitao, M. Ishizaki and M. Asaeda, Separation of solvent/water mixtures by porous membrane, in: Proc. First Int. Cong. on Inorg. Membranes '89 (L. Cot, Ed.), Montpellier, France, 3-6 July, 1990, pp. 231-236.

9 S.J. Gregg and K.S.W. Sing, Adsorption, Surface Area and Porosity, Academic Press, London, 196.

10 E.R. Gilliland, R.F. Baddour and G.P. Perkinson, Diffusion on surfaces. I. Effect of concentration on the diffusivity of physically adsorbed gases, Ind. Eng. Fundam., 13 (1974) 100-105.
11 P. Eberley and D. Vohsberg, Diffusion of $\mathrm{C}_{6} \mathrm{H}_{6}$ and inert gases through porous media at elevated temperatures and pressures, Trans. Faraday Soc., 61 (1965) 2724.

12 H. Rhim and S.T. Hwang, Transport of capillary condensate, J. Colloid Interf. Sci., 52 (1975) 174.

13 R. Toei, H. Imakoma, H. Tamon and M. Okazaki, Water transfer coefficient in porous body, J. Chem. Eng. Jpn., 16(5) (1983) 364.

14 E.A. Flood and M. Huber, Thermodynamic considerations of surface regions, adsorbate pressures, adsorbate mobility and surface tension, Can. J. Chem., 33 (1955) 203.

15 E. Gilliland, R.F. Baddour and J.L. Russel, Rates of flow through microporous solids, AIChE, 4 (1958) 90.

16 M. Okazaki, H. Tamon and R. Toei, Interpretation of surface flow phenomenon of adsorbed gases by hopping model, AIChE J., 27 (1981) 262-270.

17 R.J.R. Uhlhorn, Ceramic membranes for gas separation: synthesis and transport properties, Ph.D. Thesis, University of Twente, Enschede, 1990.

18 H. Tamon, M. Okazaki and R. Toei, Flow mechanism of adsorbate through porous media in presence of capillary condensate, AIChE J., 27(2) (1981) 271-277.

19 K.H. Lee and S.T. Hwang, The transport of condensible vapors through a microporous Vycor glass membrane, J. Colloid. Interf. Sci., 110(2) (1986) 544-555.

20 K.S.W. Sing (Ed.), IUPAC report: Reporting physisorption data for gas/solid systems (recommendations 1984), Pure Appl. Chem., 57 (4) (1985) 603.

21 B.D. Smith and R. Srivasts, Physical Science Data 25: Thermodynamic data for pure compounds (part A), Elsevier, Amsterdam, 1986.

22 C.L. Yaws, Physical properties: a guide to the physical, thermodynamic and transport property data of industrially important chemical compounds, Chem. Eng. Publication, McGraw-Hill, New York, NY, 1977.

23 R.J.R. Uhlhorn, K. Keizer, A.J. Burggraaf, Gas transport and separation with ceramic membranes. Part II. Synthesis and separation properties of microporous membranes, J. Membrane Sci., 66 (1992) 271. 